\title{
Pseudo-Invariant Feature Selection for Crosssensor Optical Satellite Images
}

Lino Garda Denaro', Bo-Yi Lin¹, Muhammad Aldila Syariz, Lalu Muhamad Jaelani² and Chao-Hung Lin ${ }^{1 *}$

${ }^{1}$ Department of Geomatics, National Cheng-Kung University, Taiwan

${ }^{2}$ Department of Geomatics Engineering, Institut Teknologi Sepuluh Nopember, Indonesia

Corresponding author: Chao-Hung Lin, Department of Geomatics, National Cheng-Kung University, Taiwan, Tel: 062757575; E-mail: linhung@mail.ncku.edu.tw

Received April 08, 2018; Accepted April 30, 2018; Published May 02, 2018

\section{Retraction Note:}

The article entitled "Pseudo-Invariant Feature Selection for Crosssensor Optical Satellite Images" has been accepted for publication in the Journal of Remote Sensing \& GIS considering the statements provided in the article as personal opinion of the author which was found not having any conflict or biasness towards anything. As the article was a perspective one, information provided by the author was considered as an opinion to be expressed through publication.

Publisher took decision to make the article online solely based on the reviewers suggestion which considered the article not but a personal opinion of the author. However, it is found that the author have some personal concerns and issues, therefore, being retracted from the journal 